\title{
Penerapan Mobile Government Pada Monitoring Aktigitas Aparatur Sipil Negara Di Dinas Komunikasi dan Informatika Kabupaten Bandung Barat
}

\author{
ASEP ID HADIANA ${ }^{1}$, FAIZA RENALDI ${ }^{2}$ \\ 1,2 Fakultas Sains dan Informatika, Universitas Jenderal Achmad Yani \\ Email: faiza.renaldi@gmail.com
}

\begin{abstract}
ABSTRAK
The development of mobile and mobile technology has given the Government the opportunity to utilize Mobile Information and Communication Technology (M-ICT) to help facilitate daily administration and to provide better services to citizens, businesses and government institutions through the use of mobile technology. The number of cellular telephone users in Indonesia continues to grow and now it has reached 50.6 million customers. Therefore, the application of $m$-Government in Indonesia is an interesting material to be studied. There are many forms of services that can be provided by m-Government, one of which is service in government offices for stakeholders of the state civil apparatus. This research takes place in the Office of Communication and Information (Diskominfo), which is one part of the Regional Work Unit (SKPD) in West Bandung Regency, and focuses on the existence of monitoring activities of the State Civil Apparatus (ASN) in the SKPD. ASN always plays an important role in the daily activities of the government bureaucracy, therefore it is necessary to manage employee data in order to achieve quality assurance on employee performance. Diskominfo West Bandung Regency has a number of employees of approximately 150 employees spread in 3 fields. The use of M-Government technology is believed to be able to provide a necessity to resolve the challenges that must be overcome, one of which is the external office / city monitoring of the ASN Diskominfo. This research will build a $\mathrm{m}$ Government application in Diskominfo, West Bandung Regency to monitor the activities of the state civil apparatus (ASN), which uses smart cellphones based on Android as its media.
\end{abstract}

Kata kunci: M-Government, Diskominfo Kabupaten Bandung Barat, Aplikasi Monitoring ASN berbasis Android; kinerja pegawai. 


\section{PENDAhUlUAN}

Pemanfaatan teknologi mobile oleh pemerintah semakin marak diimplementasikan, yang sering disebut sebagai m-Government (Mobile Government). M-Government didefinisikan sebagai strategi dan implementasi yang melibatkan penggunaan semua jenis teknologi mobile dan nirkabel, layanan, aplikasi, dan peralatan untuk meningkatkan manfaat ke semua pihak yang terlibat dalam e-government termasuk warga negara, pengusaha, dan semua unit pemerintahan (Kushchu and Kuscu, 2004). M-Government bukanlah pengganti dari egovernment melainkan aplikasi lain dari e-government (Goyal and Seema Purohit, 2012).

Walau penerapan $\mathrm{m}$-Government menjanjikan perbaikan terhadap layanan organisasi atau masyarakat, m-Government juga mempunyai risiko dan tantangan untuk diterapkan. Resiko dan tantangan tersebut didasari adanya keberagaman dalam jenis dan tingkat layanan serta faktor adopsi layanan m-Government (Shaareef et al., 2011). Keberagaman tingkat dan faktor adopsi tersebut sangat tergantung konteks masyarakat dan jenis layanan yang diterima (Lee, 2005). Penerapan teknologi baru seperti $\mathrm{m}$-Government di pemerintahan perlu dilakukan secara seksama. Hal ini mengingat banyak masyarakat yang terlibat dalam layanan pemerintah serta adanya investasi yang dilakukan menggunakan dana publik (Rannu et al., 2010).

Di sisi lain, salah satu kunci sukses keberhasilan organisasi adalah pegawai, sehingga pengelolaannya harus dilakukan dengan baik agar mampu mencapai berbagai tujuan organisasi tersebut. Pemerintahan kabupaten Bandung Barat sudah menggunakan sistem informasi manajemen kepegawaian, temasuk di Dinas Komunikasi dan Informatika (Diskominfo). Namun implementasinya masih terbatas pada pencatatan administratif dan belum terintegrasi dengan baik dari sisi penyelenggaraan kegiatan operasional kepegawaian sehingga kurang efektif untuk menangani permasalahan holistik kepegawaian dalam dinas yang bersangkutan. Oleh karena itu, perbaikan sistem informasi manajemen sumber daya manusia di Diskominfo Bandung Barat dilakukan secara bertahap, salah satunya dengan mGovernment untuk melakukan pengawasan (monitoring) terhadap aktifitas Aparatur Sipil Negara (ASN) yang berjumlah 150 orang saat ini.

Dengan tujuan untuk menjaga kualitas penampilan artikel di dalam jurnal, para penulis diharuskan memperhatikan dengan seksama seluruh ketentuan yang dijelaskan di bawah ini. Mohon diperhatikan bahwa format artikel akan diperiksa terlebih dahulu oleh Redaksi Pelaksana. Dewan Redaksi akan mengembalikan artikel yang dikirimkan namun menyimpang jauh dari ketentuan penulisan ini, sebelum diperiksakan kepada Mitra Bestari (Reviewer/Pakar) yang sesuai dengan bidang keilmuan artikel. Keputusan Mitra Bestari mengenai kelayakan artikel untuk dimuat dalam jurnal bersifat mutlak dan sepenuhnya menjadi hak Jurnal. Review oleh Mitra Bestari dilakukan secara anonim (blind-review), yaitu kedua belah pihak tidak saling mengetahui. Jika dibutuhkan, penulis selalu dapat berkonsultasi dengan Dewan Redaksi mengenai pemuatan artikel dalam jurnal.

(Meier, 2012)

\section{KAJIAN LITERATUR}

Dari subyek interaksinya $\mathrm{m}$-Government dapat dibagi menjadi empat kategori yaitu $\mathrm{m}$ Government to citizen (mG2C), m-Government to business (mG2B), m-Government to employee (mG2E) dan m-Government to government (mG2G) (Mengistu, Zo and Rho, 2009). Beberapa penelitian terdahulu menerapkan $\mathrm{m}$-Government untuk pelayanan masyarakat di United Arab Emirates (Ahmad and Khalid, 2017), Turki (Kurfalı et al., 2017), dan Inggris (Brown et al., 2017). Salah satu kesulitan dari mG2C adalah penerimaan dan respon masyarakat (S. Y. Hung, Chang and Kuo, 2013), (Nugraheni, 2011), (Almarashdeh and 
Alsmadi, 2017). Bagi negara berkembang m-Government menjanjikan (Mengistu, Zo and Rho, 2009) dan mengatasi infrastruktur dan jaringan komunikasi yang bermasalah selama ini. Beberapa penelitian mengangkat $\mathrm{mG} 2 \mathrm{E}$ yang digunakan pemerintah untuk karyawannya (OECD, ITU and Publishing, 2011), dan dampaknya (Stefanovic et al., 2016). Hal yang juga sangat penting adalah adopsi $\mathrm{m}$-Government mengidentifikasi teknologi, konteks dan lingkungan (Wang, Lu and Feng, 2011).

M-Government adalah aplikasi dari e-Government yang menggunakan teknologi komunikasi bergerak sebagai platform antarmukanya. M-Government menggunakan teknologi informasi dan komunikasi mobile dengan jaringan nirkabel oleh instansi pemerintah sektor publik untuk memberikan layanan masyarakat, aparatur dan komunikasi antar pemerintah yang cukup efisien. Karakteristik utama dari layanan mGovernment mencakup layanan pengiriman tanpa konektivitas fisik, portabilitas bagi konsumen untuk menerima layanan secara mandiri atau independen. Penyedia layanan yang menggunakan kemampuan perangkat mobile untuk menghadirkan layanan yang diperlukan, seperti masyarakat, pegawai, bisnis ataupun antar kantor pemerintah.

Dalam membangun m-Government, perlu diperhatikan kerumitan pengelolaan dan besarnya risikonya (Rannu et al., 2010). Tingkatan tersebut yaitu: Listen Level, Notification Level, Pull Based Information Level; Communication Level, Transaction Level dan Integration Level. Untuk mG2E lebih diarahkan Communication Level.

\section{METODE PENELITIAN}

M-Government monitoring aparatur sipil negara (ASN) untuk Dinas Komunikasi dan Informatika kabupaten Bandung Barat dilakukan dengan tahapan:

a. Identifikasi kebutuhan $\mathrm{m}$-Government untuk monitoring aparatur sipil negara untuk Dinas Komunikasi dan Informatika kabupaten Bandung Barat.

b. Analisis sistem berjalan monitoring aparatur sipil negara untuk Dinas Komunikasi dan Informatika kabupaten Bandung Barat.

c. Perancangan perangkat lunak m-Government monitoring ASN.

d. Implementasi perangkat lunak dan perbaikan

Strategi penelitian diperlihatkan pada fishbone pada Gambar 1.

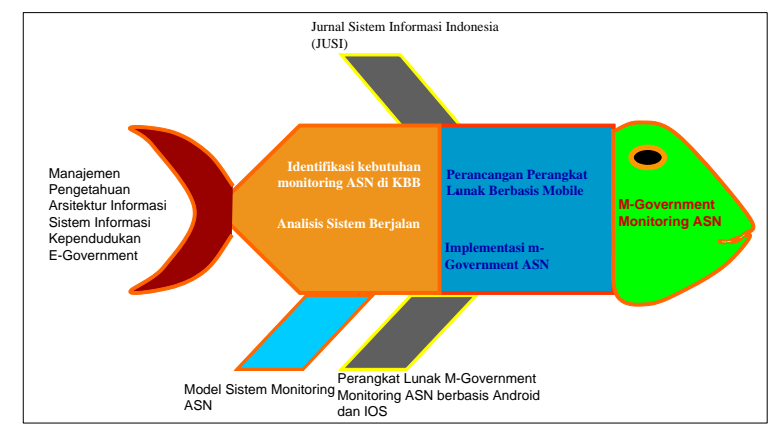

Gambar.1 Alir penelitian m-Government monitoring ASN 
Penerapan Mobile Government Pada Monitoring Aktigitas Aparatur Sipil Negara Di Dinas Komunikasi dan Informatika Kabupaten Bandung Barat

\section{HASIL DAN PEMBAHASAN}

Pada penelitian ini telah dihasilkan aplikasi m-Government di Diskominfo Kabupaten Bandung Barat untuk monitoring aktifitas aparatur sipil negara (ASN), yang menggunakan telepon seluler pintar berbasis android sebagai medianya. Tampilan aplikasi $\mathrm{m}$-Government aktifitas aparatur sipir negara (ASN) diperlihatkan pada Gambar 2.

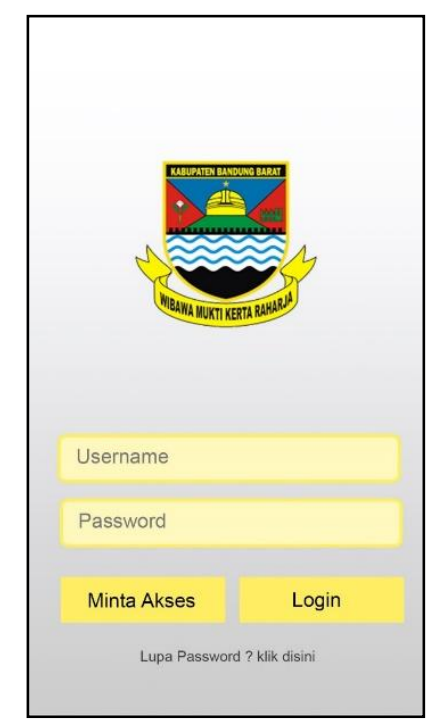

Gambar 2. Aplikasi m-Government aktivitas aparatur sipil negara (ASN)

Fitur-fitur Sistem Monitoring Aktivitas ASN di Dinas Kominfo Bandung Barat adalah

1. Proses Kelola Data Pegawai

2. Proses Pengajuan Cuti

3. Proses Pengajuan Pelatihan

4. Proses Presensi

5. Proses Chat Antar ASN

6. Proses Modul Prestasi

7. Proses Kelola Daftar Urut Kepangkatan (DUK)

8. Proses Kelola Permohonan Perjalanan Dinas

Setelah melakukan login, berikut merupakan beranda aplikasi m-Government seperti pada Gambar 3. 


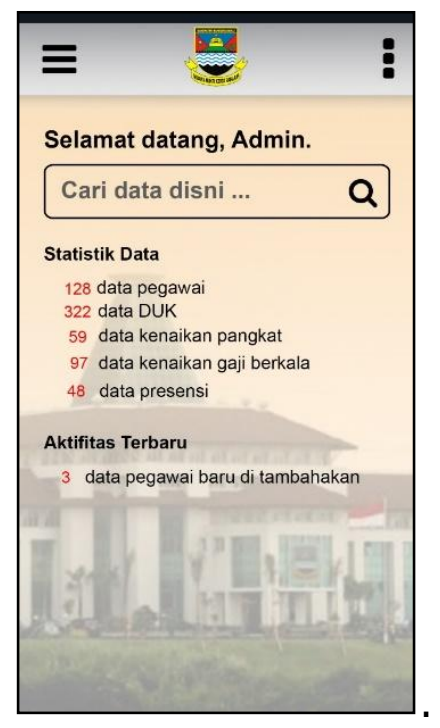

\section{Gambar 3. Implementasi Halaman Beranda}

Aplikasi m-Government di Diskominfo Kabupaten Bandung Barat untuk monitoring aktifitas aparatur sipil negara (ASN) yang telah diterapkan dilakukan pengujian dengan melalui beberapa responden sebagai sampel uji untuk menilai menguji kesesuaian aplikasi. Pengujian oleh responden ini melalui dua bagian yaitu mendata karakteristik responden dan statistika dari daftar pertanyaan-pertanyaan yang mewakili variabel yang di uji. Karakteristik responden dipetakan berdasarkan jenis kelamin, usia, jabatan dan pendidikan. Adapun kriteria responden secara rinci disajikan dalam Tabel 1.

Tabel 1 Kriteria Responden

\begin{tabular}{|c|c|c|c|}
\hline Keterangan & Kriteria & Frekuensi & Persentase \\
\hline \multirow[t]{2}{*}{ Jenis Kelamin } & $\begin{array}{l}\text { Laki Laki } \\
\text { Perempuan }\end{array}$ & $\begin{array}{l}5 \\
5 \\
\end{array}$ & $\begin{array}{l}50 \% \\
50 \% \\
\end{array}$ \\
\hline & Jumlah & 10 & $100 \%$ \\
\hline \multirow[t]{2}{*}{ Usia } & $\begin{array}{l}\text { 21-30 Tahun } \\
\text { 31-40 Tahun } \\
\text { 41-50 Tahun } \\
\end{array}$ & $\begin{array}{l}3 \\
5 \\
2 \\
\end{array}$ & $\begin{array}{l}30 \% \\
50 \% \\
20 \% \\
\end{array}$ \\
\hline & Jumlah & 10 & $100 \%$ \\
\hline \multirow[t]{2}{*}{ Jabatan } & $\begin{array}{l}\text { Junior } \\
\text { Senior }\end{array}$ & $\begin{array}{l}7 \\
3\end{array}$ & $\begin{array}{l}70 \% \\
30 \%\end{array}$ \\
\hline & Jumlah & 10 & $100 \%$ \\
\hline \multirow[t]{2}{*}{ Pendidikan } & $\begin{array}{l}\text { S1 } \\
\text { S2 }\end{array}$ & $\begin{array}{l}8 \\
2\end{array}$ & $\begin{array}{l}80 \% \\
20 \%\end{array}$ \\
\hline & Jumlah & 10 & $100 \%$ \\
\hline
\end{tabular}

Pertanyaan yang diajukan kepada responden meliputi pemberian skor terhadap aspek yang memiliki kesesuaian terhadap variabel uji. Aspek-aspek tersebut di interpetasikan dalam skala seperti yang diperlihatkan pada tabel 2 . 
Penerapan Mobile Government Pada Monitoring Aktigitas Aparatur Sipil Negara Di Dinas Komunikasi dan Informatika Kabupaten Bandung Barat

Tabel 2. Interpretasi Skor Uji

\begin{tabular}{|c|c|c|}
\hline No. & Skor & Interpretasi \\
\hline 1. & 5 & Sangat Baik \\
\hline 2. & 4 & Baik \\
\hline 3. & 3 & Cukup Baik \\
\hline 4. & 2 & Kurang \\
\hline 5. & 1 & Sangat Kurang \\
\hline
\end{tabular}

Aspek yang akan dinilai oleh responden untuk menguji kesesuaian aplikasi m-Government tersebut meliputi aspek:

1. Efektif dan efisiensi dalam penggunaan

2. Reliabilitas atau kehandalan dalam peng

3. Usabilitas atau ketepatan penggunaan

Data hasil penilaian responden disajikan kedalam tabel perhitungan hasil jawaban responden yang diperlihatkan pada tabel 3

Tabel 3. Perhitungan Hasil Penilaian Responden

\begin{tabular}{|c|c|c|c|c|c|c|c|c|c|c|c|}
\hline \multirow{2}{*}{ No. } & \multirow[t]{2}{*}{ Interpretasi } & \multirow[t]{2}{*}{ Skor } & \multicolumn{3}{|c|}{ Frekuensi } & \multicolumn{3}{|c|}{ Hasil } & \multicolumn{3}{|c|}{ Persentase } \\
\hline & & & A1 & A2 & A3 & A1 & A2 2 & A3 & A1 & A2 & A3 \\
\hline 1. & Sangat Baik & 5 & 7 & 6 & 9 & 35 & 30 & 45 & 70 & 60 & 90 \\
\hline 2. & Baik & 4 & 2 & 3 & 1 & 8 & 12 & 4 & 20 & 20 & 10 \\
\hline 3. & Cukup Baik & 3 & 1 & 1 & 0 & 3 & 3 & 6 & 10 & 20 & 0 \\
\hline 4. & Kurang & 2 & 0 & 0 & 0 & 0 & 0 & 2 & 0 & 0 & 0 \\
\hline 5. & Sangat Kurang & 1 & 0 & 0 & 0 & 0 & 0 & 0 & 0 & 0 & 0 \\
\hline \multicolumn{3}{|c|}{ Jumlah } & 10 & 10 & 10 & 46 & 4.5 & 49 & 100 & 100 & 100 \\
\hline \multicolumn{6}{|c|}{ Rata-rata item aspek pertanyaan } & 4.6 & 4.5 & 4.9 & & & \\
\hline \multicolumn{6}{|c|}{ Rata-rata penilaian responden } & & 4.7 & & & $94 \%$ & \\
\hline
\end{tabular}

\section{KESIMPULAN}

Aplikasi m-Government monitoring aktifitas aparatur sipil negara (ASN) dapat mempermudah kegiatan adminstratif kepegawaian terlebih dengan kemampuan sistem yang ditekankan kepada interaksi yang lebih interaktif dimana pegawai dilibatkan didalam sistem seperti melakukan pengisian peremajaan data yang dilakukan didalam sistem dan dikoreksi secara langsung oleh kepegawaian apabila terdapat data atau persyaratan yang tidak valid. Pegawai juga mampu mengajukan menjadi peserta diklat, mengajukan cuti dan mengajukan mutasi dini dimana pegawai dapat melampirkan persyaratan dari setiap kegiatan adminstratif tersebut serta mampu mendapatkan informasi status dari kegiatan adminstratif yang sedang dilakukan. Begitu juga pihak kepegawaian Diskominfo dengan adanya sistem informasi manajemen kepegawaian ini mampu lebih membantu dan meningkatkan kemampuan pengelolaan dalam hal kelola data dan penyajian informasi yang diharapkan terhindar dari inkonsistensi data, 
dengan informasi yang disajikan melalui grafik kepegawaian juga mampu mendapatkan informasi dengan mudah yang menunjang bagi kegiatan adminstratif kepegawaian.

Berdasarkan hasil pengujian terhadap aplikasi m-Government di Diskominfo Kabupaten Bandung Barat untuk monitoring aktifitas aparatur sipil negara (ASN) diperoleh hasil uji responden menunjukan rata-rata penilaian responden sebanyak 4.6 atau tingkat keberhasilan sebesar $92 \%$, dimana semua fungsi telah sesuai dengan yang diharapkan.

\section{DAFTAR RUJUKAN}

A., G. and Merkuryeva (2006) 'Demand for online government services: Case studies from St. Petersburg', Information Polity, pp. 241-254.

Acker, J. C. and Mbiti, I. M. (2010) 'Mobile Phones and Economic Development in Africa', Journal of Economic Perspectives, 24(3), pp. 207-232. Available at: http://sites.tufts.edu/jennyaker/files/2010/09/aker_mobileafrica.pdf.

Ahmad, S. Z. and Khalid, K. (2017) 'The adoption of M-government services from the user 's perspectives: Empirical evidence from the United Arab Emirates', International Journal of Information Management. Elsevier, 37(5), pp. 367-379. doi: 10.1016/j.ijinfomgt.2017.03.008.

Almarashdeh, I. and Alsmadi, M. K. (2017) 'How to make them use it? Citizens acceptance of M-government', Applied Computing and Informatics. King Saud University, pp. 1-6. doi: 10.1016/j.aci.2017.04.001.

Brown, A. et al. (2017) 'Appraising the impact and role of platform models and Government as a Platform (GaaP) in UK Government public service reform: Towards a Platform Assessment Framework (PAF)', Government Information Quarterly. Elsevier Inc. doi: 10.1016/j.giq.2017.03.003.

Goyal, E. and Seema Purohit (2012) '2012 Emergence of m-Government The Way Forward.pdf', SIES Journal of Management, 8(1), pp. 56-66.

Hawking, P., Stein, a and Foster, S. (2004) 'e-HR and employee self service: a case study of a victorian public sector organisation', Issues in Informing Science and Information Technology, 1, pp. 1017-1026. Available at: http://informingscience.org/proceedings/InSITE2004/128hawki.pdf.

Hung, S.-Y. Y., Chang, C.-M. M. and Kuo, S.-R. R. (2013) 'User acceptance of mobile egovernment services: An empirical study', Government Information Quarterly. Elsevier Inc., 30(1), pp. 33-44. doi: 10.1016/j.giq.2012.07.008.

Hung, S. Y., Chang, C. M. and Kuo, S. R. (2013) 'User acceptance of mobile e-government services: An empirical study', Government Information Quarterly. Elsevier Inc., 30(1), pp. 33-44. doi: 10.1016/j.giq.2012.07.008.

Kurfalı, M. et al. (2017) 'Adoption of e-government services in Turkey', Computers in Human Behavior, 66, pp. 168-178. doi: 10.1016/j.chb.2016.09.041.

Kushchu, I. and Kuscu, M. H. (2004) 'From E-government to M-government: Facing the Inevitable', in Proceedings of the 3rd European Conference on eGovernment, pp. 253-250. Available at: http://citeseerx.ist.psu.edu.

Lee, D. H. (2005) 'Contextual IT Business Value and Barriers : an E-Government and E-Business Perspective', in Proceedings of the 38th Hawaii International Conference on System Sciences - 2005 Contextual, pp. 1-10.

Li, X. J., Guan, Z. L. and Fan, L. (2009) 'Analysis of mobile government's influences on government managements', in Proceedings - International Conference on Management and Service Science, MASS 2009. Wuhan, China, pp. 1-4. doi: 10.1109/ICMSS.2009.5305875.

Mengistu, D., Zo, H. and Rho, J. J. (2009) 'M-Government: Opportunities and Challenges to Deliver Mobile Government Services in Developing Countries', in 2009 Fourth International 
Conference on Computer Sciences and Convergence Information Technology MGovernment:, pp. 1445-1450. doi: 10.1109/ICCIT.2009.171.

Nugraheni (2011) 'Citizen Centered Models Using Mobile Technology', jurnal Matematika, 14(3).

OECD, ITU and Publishing, O. (2011) M-Government: Mobile Technologies for Responsive Governments and Connected Societies. doi: 10.1787/9789264118706-en.

Rannu, R. et al. (2010) Mobile Government: 2010 and Beyond, White Paper.

Rao, V. R. (2011) 'Collaborative Government to Employee (G2E): Issues and Challenges', Journal Journal of E-Governance, 34(4), pp. 214-229.

Rao, V. R. (2017) 'Improving Government to Employee ( G2E ) Services through Mobile Technology - A Survey', 168(6), pp. 33-45.

Ruël, H., Bondarouk, T. and Looise, J. (2004) 'E-HRM: Innovation or irritation. An explorative empirical study in five large companies on web-based HRM', Management Revue, 15(3), pp. 364-381. Available at: http://www.jstor.org/stable/41783479.

Schno, H. J. (2015) 'E-Government: Information, Technology, and Transformation', Routledge. Schnoll, H. J. (2015) E-Government: Information, Technology, and Transformation. Routledge.

Shaareef, M. A. et al. (2011) 'e-Government Adoption Model (GAM): Differing service maturity levels', Government Information Quarterly. Elsevier B.V., 28(1), pp. 17-35. doi: 10.1016/j.giq.2010.05.006.

Stefanovic, D. et al. (2016) 'Assessing the success of e-government systems: An employee perspective', Information and Management, 53(6), pp. 717-726. doi: 10.1016/j.im.2016.02.007.

Tang, H. (2011) 'Using Association Rules Mining to Provide Personalized Information in EGovernment', in International Conference E -Business and E -Government (ICEE). China.

Al Thunibat, A., Zin, N. A. M. and Sahari, N. (2011) 'Mobile Government User Requirements Model', Journal of EGovernance, 34, pp. 104-111. Available at: http://content.iospress.com/articles/journal-of-e-governance/gov00260.

Wang, C., Lu, Z. and Feng, Y. (2011) 'M-government Use: Technology, Context and Environment Determinants', in 2011 International Conference of Information Technology, Computer Engineering and Management Sciences M-government, pp. 290-293. doi: 10.1109/ICM.2011.320. 